\title{
A Critical Look at the Success of Development Journalism in Ethiopia
}

\section{Solomon Tabor*}

Dilla University, Ethiopia

\begin{abstract}
The article focusses on assessing whether development journalism is successful in government media or not. The paper has been presented to public lectures and seminars. The purpose of this essay is to address the question that to what extent the employment of the model is successful. Though the question at hand calls for a quantitative data analysis, this specific article attempts to addresses it descriptively and the thesis statement of this article is that it is too difficult to claim that development journalism in Ethiopia is successful or rather the extent of success of DJ in Ethiopia is quite low.
\end{abstract}

Keywords: Development; Journalism; Editorial; Independence; Mobilization; Mass participation; Corrupt practices

\section{Introduction}

As known, development has been the key target and agenda of the Ethiopian government. The notion cuddles different facets of development including political, social, economic, infrastructure, societal, environmental, and intellectual aspects. Consequently, the government media are made to play an essential role in mediating the development in the country. And development journalism model has been used as a guiding philosophical working principle with in the government media. However, this does not completely mean that it does not have a merit within the government mass media. Hence, the purpose of this essay is to capitalize or to make vivid how the practice of DJ in government media has been poorly taken care of.

\section{Is the Model Apposite for Ethiopia?}

Before submerge into the depth of the argument that is as to how the theory/model has been inappropriately used or purposely modified to fit for purpose unlike the true nature of it, it is compulsory to look into whether the notion is worth apt or not. By looking into the tenets of the model and the economic and political ideology of the country, one can handily conclude that the model can serve the purpose. The Ethiopian government development policy clearly stipulates that mobilizing the society at all levels is indispensable for the realization of the development plan. And this for granted is up to the media [1]. And the overriding principle of DJ is to echo and mobilize for development goals. As can be noted above, there seems to be a common denominator between the government's development policy and the notion of the model.

Investigative journalism can be found being sandwiched into DJ or IJ is within DJ and this is the other reason why the notion of the model will be imperative for Ethiopia where corruption and corrupt leadership has become a major concern. According to Murthy In its treatment, development journalism is not different from investigative reporting. He further explains that a development journalist should critically examine, evaluate and report the relevance of a development project to national and local needs, the difference between its impacts on people as claimed by the government officials and as it actually is. It is not synonymous with officially prepared handouts, so-called positive news [2].

Thirdly, for a country that waged socio-economic and political development, mobilization and intensive participation of the inhabitants are inevitable. And DJ is ideal for this purpose. Among the tenets of the model is to mobilize and create mass participation. To this end Banda [3] claims that Development Journalism has to Motivate the audience to actively cooperate in development. It is a mere fact that development will only be a nightmare without a hearty engagement of citizens. For this to happen, the notions of DJ have a paramount significance to move the mass for a common agenda.

The fourth point is from the perspective of the audience. The part and parcels of the model that makes it crucial for a country like Ethiopia is that it gives a due regard towards the needs, rights and demands of the audience. So how does DJ enable the audience to be lucrative? DJ enables the journalist to work for the interests of those concerned. The popular saying 'journalism is a voice for the voiceless' has a prominent place in DJ too. The weak, vulnerable, poor, victims of strife political situations, homeless.... And the likes will have their say in a media that hold DJ as a guiding principle. And to put it in simple terms Ethiopia is a home for those mentioned and unmentioned socio-economic and political evils. Hence, DJ can cling on in Ethiopian media for good.

Fifthly, from normative framework point of view, the model is indispensable. That is In considering the normative character of development journalism, McQuail [4] prescribed the following attributes: The media must accept and carry out positive development tasks in line with nationally established policy; freedom of the media should be open to the economic priorities and development needs of the society; media should give priority in news and information to links with other developing countries which are close geographically, culturally and politically, among other attributes. Hence the normative framework of the model necessitates the need to employ it in a country likes Ethiopia.

The sixth rationale that calls for the need for the model is its pragmatic essentiality. Since, the government of Ethiopia is promulgating the development issue day in and day out, a media philosophy that can bind up the nation around the issue and yet critically evaluate the progress is crucial. And DJ, for grunted, can serve

*Corresponding author: Solomon Tabor, Dilla University, Ethiopia, Tel +251461310001; E-mail: sol.asniti@gmail.com

Received June 08, 2018; Accepted October 06, 2018; Published October 12, 2018

Citation: Tabor S (2018) A Critical Look at the Success of Development Journalism in Ethiopia. J Mass Communicat Journalism 8: 393. doi: 10.4172/21657912.1000393

Copyright: (c) 2018 Tabor S. This is an open-access article distributed under the terms of the Creative Commons Attribution License, which permits unrestricted use, distribution, and reproduction in any medium, provided the original author and source are credited. 
the purpose. Among the manifestations of the pragmatic consequence of the model within the government media, though little in number, are 'Fit le Fit' in EBC, 'Yeketemotch mederek, in AMME and some more news stories broadcasted by regional media agencies and EBC.

\section{How Successful is the Model So Far?}

Though researches witness that the model is not implemented as it is supposed to be or as per its strong tenets dictates, with all the pragmatic limitations, the government media has done a promising job with it. McCombs and Shaw [5] have come up with the following tasks that any media that employ DJ as a working philosophy should undertake. Hence, the recommended tasks that a development propagating media supposed to commence are tasks of mobilizing the public and creating mass participation, adopting new innovations and technologies among the rural and sub-urban community, creating awareness and preparing for further action, To clarify policies and strategies, serving as a multiplier of change, exposing corruption and corrupt practices, avowing public complaints and compliments, questing the quality of public service offices.

\section{Mobilization and creating mass participation}

Perhaps the most successful accomplishment of the government media in making use of the DJ model is mobilizing the public for participation in Grand National projects and national threats. For instance, the so called the great renaissance dam project has received a lot and frequent coverage by both print, online and broadcast media of the government and has achieved in creating mass participation and donation for the dam. The media strived to picture the dam as a national icon that can unify the diverse nations and nationalities as one. Moreover, the development propagating media echoed the fact that building a dam over the river 'Abay' which has never been succeeded by the previous regimes in fear of the political vibe and financial shortcomings has added another verve and energy to the mobilization and mass participation of the public. Mobilizing the public to assist in drought stricken areas and the demonstrations in favor the great renaissance dam are among the manifestations.

\section{Adopting new innovations and technologies}

Since the government's development policy reckons on the rural development to bring about sustainable food sufficiency and through time to give birth to industrialization, the media frequently resonance the need for the farmer to adopt new agricultural practices. EBC's, formerly ETV, news, news analysis and programs, the radio programs and the government newspapers' front pages report and ricochet the success of development agents (DAs) in introducing the farmers with new agricultural technologies and practices. So DJ applauded DA.

\section{Creating awareness and preparing for further action}

The chief propeller of the development in the country, as known, is the farmer, hence, the development propagating media need to keep abreast of local, continental and international affairs and aware the majority rural community to work for a better future and earn better than ever. In cautioning the farmer with probable risks from nature and alerting to nurture the nature has so far been among the development agenda of the media. To cite manifestations, the programs on deforestations and afforestation's and the news on cautioning the farmer to protect growing crops from unseasonal rains and the likes can be an example.

\section{To clarify policies and strategies}

It is a well-known fact that among the duties of a professional journalist is to serve as a golden bridge between the government and the public. Thus, presenting, clarifying policies and strategies to the public and taking back criticisms, comments and the likes to the government. By the same token, the development journalist too need serve the same purpose. To this end, the government media are successful in letting know the public with new and amended policies and strategies but not as such successful in taking back the complaints, compliments and criticisms.

\section{Serving as a multiplier of change}

To this development journalism goal end, the government media has done a good job. Particularly in singling out the succeeded and presenting them to the public so that other can learn from them has been a successful task the media has accomplished. And so the experiences of those in large scale and small scale financial, academic, innovation, agricultural ... success have filled in the TV screen, controlled the radio air time and dominated the front page of newspapers. Moreover, agricultural and industrial experiences of other countries, china for the most part, have got a pretty good coverage. And so it can be said that efforts have been made towards multiplying change.

\section{Exposing corruption and corrupt practices}

Though a lot has to be done in this regard, some efforts have been made to expose malpractices and corrupt practices. For instance, news regarding delayed road constructions, deferred housing constructions, the corruption chain within customs authority, the severe corruption within the construction sector, corruption court cases have been aired by the government media. Nevertheless, compared to the extent of corruption and corrupt practices, the government media's effort is almost trivial

\section{Avowing public complaints and compliments}

With regards to voicing the publics' complaints and compliments efforts, though not that much pronounced, have been made. For instance, complaints have been aired considering the dalliance in road construction, problems associated with electrifications and clean water supply and poor service delivery and customer handling at public service enterprises and comments of the public and intellectual on the last unrest had been given coverage. The media, particularly EBC, had been broadcasting the so called the 'peace conference' that constituted intellectuals, opposition party leaders and members, public figures and opinion leaders that held a discussion on the previous turmoil in the country. Yet, such efforts of the government media lack continuity and depth.

\section{Questing the service quality of public service offices}

The other assignment expected from a media guided by the philosophy of DJ is to look into whether public service offices are offering a service to the public as per the standard set for them. If so, setting them as an example and if not holding them responsible before the eyes of the public. To this end, the media have shown some efforts. For instance, Ethio telecom was criticized for the poor quality service delivery so was the Ethiopian electric power station, the sewerage system authority, the customs authority and the likes.

To wrap up the sub-topic, as McCombs and Shaw [5] stated the above discussed points as indicative of a media that employed DJ as a working principle, the government media has put efforts, though very limited, towards implementing the tenets of the model. However, are the above fractured accomplishments good enough to claim that the philosophy has been put into practice? Or to put it in simple terms is DJ 
being practiced in its full meaning and facets? The answer, as researches revealed and to my best understanding, is nugatory. This essay will not be full and meaningful unless it raises issues that explain why the philosophy is partly implement, very limited potion of it in fact, and the inhibiting factors that strangled the success of the model in Ethiopia, government media? And this will take us to the next sub-topic.

\section{Why Execution of the Model is Very Limited?}

Once again, even if studies have nailed it now and then, it is inevitable to show the point of departure where the model does not get its right meaning of execution in the media. The purpose of this article is not to show the holes of the philosophy rather it is to exhibit the extent of success of the model. Consequently, to weigh, qualitatively, to what extent the model is successful, it's imperative to show where things went wrong in executing the model. In doing so, one can see the effectiveness of the execution of the model on the ground. As outlined in the very first paragraph of the essay, the extent of success of the model on the ground is very low. Almost close to unsuccessful. In spite of the fact that the preceding sub-topic discussed some accomplishments, they lack continuity and depth. It seems a seasonal response to timely criticisms on the media. So what exactly tangle the actual implementation of the model?

\section{The philosophy is not taken as a big deal by the journalists}

A development journalist must know every single facets of the ideology including its holes and potencies. The query here is that do we have that kind of journalists equipped with the theoretical realm of the philosophy and willing to pay professional commitment and scarification. It is obvious, few, perhaps hardly any. So with journalists who don't, for better or worse, have what it takes to be a competent development journalist, how can one expects success? It's only a nightmare. According to Nwosu, a development journalist need to acquire the following know how and skills should be Strongly committed to the ideals of development journalism in all its facets, works for the interest of the generality of the people, give the people's initiative and ideas on development a full rein in news stories and commentaries, he /she uses all opportunities at his/her disposal to cover development news on a regular basis with devotion and a high sense of professional responsibility, and he or she is motivated in investigative reporting [6].

Hence, the issue of professionalization is in serious jeopardy here. The development journalist, no matter how the inside and outside pressures are repelling, should acquire the desired personal skills and knowledge of what makes a competent development journalist. Nonetheless, the issue does not seem to be taken as a big deal. Reading for personal growth, discussing, debating for collegial enhancement and striving to be a catalyst to bring about institutional change seems to be critically overlooked.

\section{Politics messing up the professional duty like a bad boy}

Politics, within the professional world of journalism in Ethiopia, seems to be like a nasty boy distorting and messing up everything that his mom put in place and order. In a country like ours and in a government media, it is highly unlikely to claim that politics should remain completely detached from the professional world of journalism. Hence, Researchers frequently recommended a reasonable, calculated and justifiable intervention of it, but the ears that are supposed to hear the professionals and academicians turned out to be deaf. Favoring party member journalists with organizational incentives for only being a member, denying non-members opportunities and incentives, enticing new recruits with various incentives and hidden promise to stay on the job for quite so long no matter how, recruiting party members from the very beginning, playing the fear factor with nonmember journalists, that is making them feel unsecured in every move they make, are some of the manifestations how politics intermingles with the profession.

Birhanu Olana quoting the view of a senior editor in government media asserted that Ethiopian journalism has too many "loyal cadre journos" and too much "say-so-journalism," meaning journalists faithfully report everything government officials say and, even worse, everything they think the government officials might want to be said. Terje on his part described the Ethiopian media environment as a place where there is 'social satisfaction' and 'professional dissatisfaction'. He further affirmed that" It is common knowledge that the top management of the media organizations is politically appointed and hence government-loyal. All general managers of the three state media organizations (EPA, ERTA and ENA) are picked from trusted government circles." (2012:196). Hence, the political factor has seriously mitigated the extent of success of the model.

\section{Editorial independence at a risk of wipe out}

The notions of the ideology, though not in its fullest sense, are incorporated in the editorial policy of EBC and hopefully other government media, however, the practitioners' hands are tangled for various reasons. Hence, the editorial independence is laid on the line. This, obviously, will tone down the extent of success of DJ. The gap between reality and aspiration for a newbie journalist is too great. Terje express it in such a way that "The major source of dissatisfaction, nevertheless, is lack of journalistic freedom. Re-porters come to the state media anticipating that they will follow personal journalistic ambitions, but soon feel curtailed by the organization's expectations in the daily news production" (ibid). So how on earth one can expect DJ to triumph while the editorial independence is critically in jeopardy.

The low emphasis given to it by the academic curricula and the J-schools

The curricula of J-schools is not developed in an excelled cognizant of DJ. The notion or the philosophy is not given a due emphasis in the curricula. So apart from envisaging the media scenarios in the country and giving DJ due emphasis in the curricula, the J-schools should organize discussions and debates on the merits and demerits of the notion. And should also extend their efforts of carrying out researches on development journalism so that students widen their view of the theoretical realm of the ideology and prepare themselves for the upcoming task on the actual battlefield. So the task of J-schools to produce a well cognizant, self-reliant and responsible journalist should start from by critically considering the realities on the ground and equipping the students accordingly. Not less than this is providing the notion with an appropriate focus by all the concerned academic community will contribute its part to scale up the extent of success of the model on the ground.

\section{Ambivalent acceptance of the model by journalists}

The distorted implementation of the model on the actual working area, the newsroom, enabled newbie journalists to be ambivalent of the essence of the model. So its success or effective implementation is somehow hampered and tampered by the reluctant acceptance and attempting to implement it with distorted comprehension. If only this cycle be broken that the young journalists can really bring about a change in perception concerning the model. To this end Terje pointed out that "lack of opportunities to follow one's own journalistic 
aspirations demotivates many newcomers. The routine production, writing stories according to a standard formula, be-comes a dull and uninteresting exercise" [7].

\section{Poor response rate by media organizations}

The tendency to carryout audience research, critically assessing the effectiveness of the model, examining the perception and implementation of the journalists towards the model, and conducting overall organizational study and scrutiny on permanent basis are poor that media organization couldn't possibly bring about professional change for good. The culture of conducting a research on the overall implementation of the model either by an outside expert(s) or internal organ staffed for this purpose is lethargic that the implementation on ground has become far below expectation. Hence the poor response rate by government media organization regarding matters associated with the execution of DJ resulted in a low extent of success while translating the model into practice.

\section{Westernization vs. localization saga}

The western influence is strongly reflected on the academic institutions that produce journalists for the market, on the large, heterogeneous and anonymous audience, on the media organizations too. As known, the curriculums, academic references, the online resources and the exemplifications used in the class rooms are dominantly western in nature. The audiences too, subconsciously, have taken the western media as a standard for measuring the performance of local journalism. The western medias' vibe is so strong and compelling that the audience have taken it as a standard plus the poor stature of the local media has added a gas on the fire.

The working journalist as well is massively attracted to the western media approaches, for this to happen, as mentioned above, the college education's western dominance has carved their mind. So what is the sum total of all this? It's simple, overtime, localization or local practices have given in to western ideologies. The trauma here is that the journalist will be caught up between competing interests and lose focus and confidence to implement DJ heartedly. And all those western pressures and the unprofessional execution of DJ affect the working journalist to overlook the model and through time it harms the extent of successful implementation of the model.

\section{The private press understating the model}

The divisive, distrustful and/or suspicious relations between the private and government media has also been reflected in downplaying the model by the part of the private journalists. A research conducted on the private and government journalists' perception towards DJ revealed that some private journalists hardly support the employment of the model by the government media. And they highly associate it as a political freight imposed on the media by the government. As the government claimed that it is a "development government" and as a result adopted development journalism to be the constitution of the government media. This assumption inhibited most of the private media journalist to delve into the philosophy and do their part. The common name calling of the private and government media journalists as 'development inhibitors' and 'development propellants' suggest that there seems to be an antagonistic view in terms of comprehending and defining the actual development in the country. And this, obviously, mitigates the extent of DJ in the country.

\section{Conclusion}

The purpose of this essay is to reveal the extent of success of employing DJ model in Ethiopia. As clearly stipulated in the very the first and second sub-topics the model, for mentioned grounds, is apposite for Ethiopia. Its investigative nature in case of mal practices, participatory nature to engage in the audiences, its aspect of national contribution as it creates a wide room for development coverage, its social responsibility part in allowing a room for coverage of the weak, vulnerable and socio-economic and political victims and the likes makes the model fit for purpose, feasible and workable.

Pertaining to its success, though it lacks continuity and depth, it allows a room for mobilizing the public and creating mass participation, adopting new innovations and technologies among the rural and sub-urban community, creating awareness and preparing for further action. To clarify policies and strategies, serving as a multiplier of change, exposing corruption and corrupt practices, avowing public complaints and compliments, questing the quality of public service offices. Consequently, even if it is not implemented in its fullest sense and meaning, the tenets of DJ have helped the practitioners to contribute for the good of the nation at large.

It is also imperative to show the missing elements or where things went wrong in putting the model into practice because it assists to create an insight to see the extent of success of employing the model. Thus, inhibiting factors like poor comprehension and professional undertaking of the model, political interference, lack of editorial independence, poor emphasis given to it by the academic community, ambivalent acceptance by the practitioners, low response rate by the media organization, western media and ideologies influence, the private media understating the model and other similar factors mitigated the extent of successful implementation of the model.

So the bottom line of the argument of this essay is that in spite of the fact that some victories have been won and the philosophy can serve the purpose for the demands of the media industry in Ethiopia, the answer for the query of to what extent the employment of DJ model can be successful in Ethiopia is very... low.

\section{References}

1. Ministry of information (2002) Issues of Building Democracy in Ethiopia. Ethiopia, Addis Ababa. Berahinina Selam Printing Enterprise.

2. Murthy DVR (2006) Development Journalism. What Next? An Agenda for the Press. India: Kanishka Publishers, New Delhi

3. Fackson Banda (2007) An appraisal of the applicability of development journalism in the context of public service broadcasting (PSB). 33: 154-170.

4. McQuail Denis (2009) Mass communication theory; London sage publication.

5. McCombs M, Shaw D (1977) The Emergence of American Political Issues New York.

6. Nwosu, Ike (1989) Writing rural news and features, rural news.

7. Skjerdal T (2012) Competing loyalties; Journalism culture in the Ethiopian state media. 